\title{
FATTY EMBOLISM OF THE RETINAL ARTERY FOUND IN EYES AFTER ENUCLEATION AND ORBITAL EXENTERATION*
}

\author{
BY
}

\author{
ARNOLD LOEWENSTEIN \\ GLASGOW \\ and \\ JOHN FOSTER \\ LEEDS
}

FROM THE TENNENT INSTITUTE OF OPHTHALMOLOEY

UNIVERSITY OF GLASGOW (PROF. W. J. B. RIDDELL)

WhILE studying the retina with the slit-lamp after equatorial opening of the excised eye, we have observed, on four occasions, the central artery to be partly filled with fat.

The first case was a malignant melanoma of the choroid in the macular area ; the second a malignant melanoma of the limbus; the third a perforating injury of the eyeball; and the fourth an exenteration of the orbit for malignant melanoma.

In three cases the eye was enucleated, and in the fourth exenterated with the orbital fat. All specimens were fixed in 10 per cent. formalin immediately after removal.

-The artery appears as a shining white band (Fig. 1) rising from the depth of the cup, while the veins may be empty or filled with

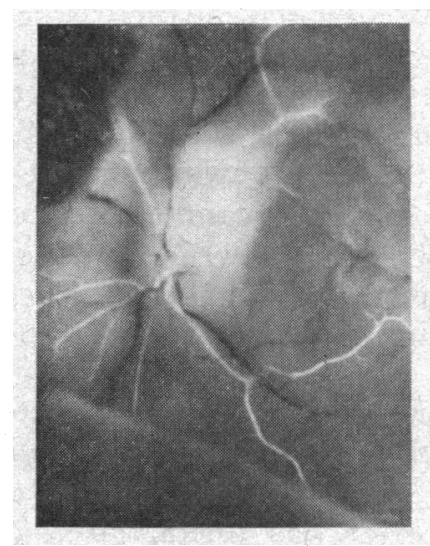

Fig. 1.

Malignant melanoma of the limbus. The central artery and the main branches are filled with a smooth whitish mass. $\times 5$ approx.

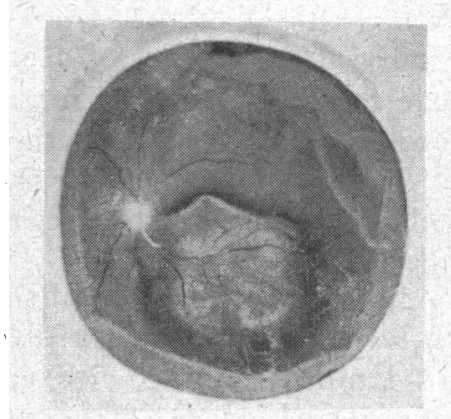

FIG. 2 .

Malignant choroidal melanoma in macular area. Lower papillary artery filled by a smooth whitish mass. $\times 2 \frac{1}{2}$ approx.

* Received for publication, June 4, 1948. 
blood. The higher magnification of the corneal microscope shợs interruptions of the milky white content of the arterial branches, whose peripheral twigs are either bloodfilled or collapsed. The white band was visible in another case (Fig. 2), $1 \frac{1}{2}$ d.d. only foom the disc, while the remaining vessels did not reveal anyth abnormal, either in their content or in the walls.

The third case, the perforating injury, showed a short white band only, while the arterial system of the fourth case was milky

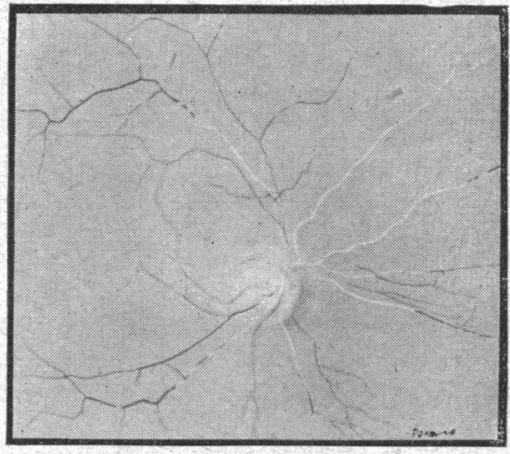

FIG. 3

Case 4. Malignant melanoma. "Exenteration of the orbit.

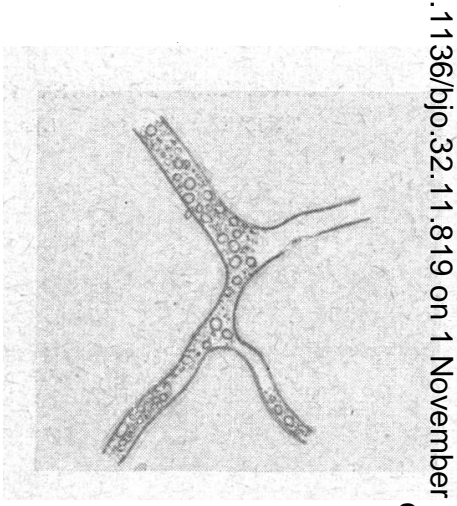

FIG. 4

ᄋํํ

Embolism, unstained retina in oil immersion. A capillary $\overline{\varphi q l i t a d}$ with an emulsion of droplets. are of various sizes (from $2 \mu$ dow

to a considerable extent (Fig. 3). The area of transition fromothe milky part to the bloodfilled lumen is empty for a short dista pice.

In some places the interrupted peripheral blood column resembled the "cattle truck" phenomenon seen ophthalmoscopically at the instant of death. Here we ought to mention that " cattle trucking" in the retinal blood vessels cannot be regarided as absolute proof of the death of a person (as a writer to the Bofit. Med. Jl. has assumed lately erroneously), but is also observe ${ }^{\prime}$ in thrombosis of the central retinal vein, or of its branches in the living eye.

The first task was to establish the nature of the vascular contênt. A disc of the retina with a piece of the milky vessel was excised with a $4 \mathrm{~mm}$. trephine, cleared with glycerine, and studied high power (Fig. 4). The white vessel was filled with a 萑ne granular mass. The size of the granules varied from $2 \mu$ downwards, the great mass of them being far smaller. The majority doubly refractile. No red blood corpuscles were found withincthe granular content.

The vessel distal to the "milky" appearance contained bl $\$ d$. 
The endothelial cells appeared normal under oil immersion. None of the four patients suffered from diabetes or lipaemia. In no case was an embolus of the central retinal artery seen prior to excision.

The bulk specimen was washed and stained for fat with scarlet red. The whole milky content was shining red, the vessel wall appeared fat free in the fat stained bulk specimen.

Another piece of retina $4 \mathrm{~mm}$. dm. was embedded in gelatine and cut with the freezing microtome and the sections stained with hematoxylin and sudan III. The fatty content appeared darker red (Fig. 5). In spite of careful handling the content of the artery fell out of several cross sections of the optic nerve in the specimen.

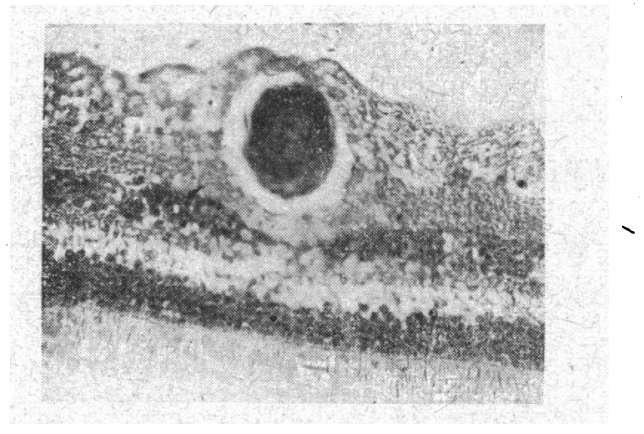

Fig. 5.

Case 4. Retinal disc $4 \mathrm{~mm}$. dm. removed, studied in bulk unstained. Embedded in gelatine, sectioned with freezing microtome stained with haemat., Sudan III. $\times 300$. The retinal artery is filled with a dark-reddish granular mass.

We came to the conclusion that all four cases could be explained by entry of a fatty embolism into the central artery. As the first cases were performed while we were using an anti-rusting substance, A.C. 10, in sterilisation, our attention was first drawn to this. This conception had to be abandoned, as A.C. 10 was not employed in the third case.

We concluded, therefore, that it was orbital fat which had intruded into the divided central artery. The scissors which had cut (unintentionally) orbital fat, had opened the central artery, probably where it pierces the optic nerve sheath $(7-12 \mathrm{~mm}$. behind the bulb). The fat was moved by the pulse wave of the artery towards the branches, and was emulsified by the arterial blood. The time lag between intrusion of the fat into the retinal artery, and excision and fixation of the bulb, was too shert to permit of pathological changes in vessel walls and retinal tissue.

Fat embolism in the retinal vessels is not as rare as Leber (1915) in his classical description has assumed. According to him no case 
has been published in which retinal function has been damage fatty embolism.

Urbanek (1933), Oppolzer (1934), Loewenstein (1936) $\stackrel{\vec{F}}{\text { Pave }}$ proved that especially after single or multiple fractures, invoging the medulla of the long bones, not only is pulmonary $\bar{c}$ and cerebral fatty embolism relatively frequent, but that retinal changes of typical appearance can be observed.

Urbanek has demonstrated that haemorrhages are as a rule the first sign, and are followed by white patches. The white foc?are predominantly. situated at the bifurcations of arteries, and they change their position. Histological investigation proved That retinal and choroidal capillaries are partly filled with fat. Urb assumes that fatty droplets pass from the bloodstream into rexinal tissue, and can disappear quickly. He called attention to the great similarity of the ophthalmoscopic picture of Purtscher's traunigatic retinal angiopathy to fat embolism of the retina.

Loewenstein (1936) collected four further cases in a short tome. $\mathrm{He}$ stressed the fact that the visual damage in this type of fatty embolism is repaired both quickly and spontaneously. The white silvery patches disappear, while the scotoma becomes "\$Perforated " before vanishing. His third case shows the ty gical ophthalmoscopic picture of the fatty embolism after a soft gissue operation.

We suppose that in these clinical cases, as in our four eye specimens, the blood is displaced by the fatty emulsion. $\%$ his

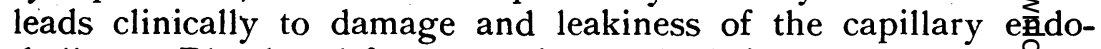
thelium. Blood and fat escape into retinal tissue.

Surface tension congeals the fatty emulsion in the retinal tis and it becomes visible ophthalmoscopically as silver white patches. As there is no other retinal vascular disease, and the retinal tissue is normal, the blood and fatty débris vanish quickly abśorption.

On the other hand, the intra-arterial fatty material is fil emulsified, and might pass through the retinal capillaries without damage to the vessel wall and retinal tissue. Both processes mitght occur simultaneously in traumatic cases.

While the occurrence of fat embolism in a retinal artery of an eye which is to be excised has no practical interest, it may throw light on the mechanics of fatty embolism generally.

We suspect that some of the symptoms ascribed to sheck generally may be in fact symptoms of fatty embolism of pulmofary and cerebral capillaries.

Our observation shows the ease with which fatty droplets enter vessels opened by accidental or operative injury.

This might be even a potential danger in foreign body extration with the posterior route. 
One feature in the causation of traumatic retinal fatty embolism can be understood only with difficulty. As these fatty droplets entering the veins (e.g., of the fatty bone marrow) arrive in the retinal arteries, they are bound to travel through the pulmonary capillary system, yet only some of the traumatic fatty embolism cases show the signs of pulmonary embolism.

Microscopic examination of unstained specimens in our four cases has shown that the intra-arterial fat is very finely emulsified. This fine emulsion might pass the pulmonary capillaries without provoking gross disturbance. We can explain the phenomenon, therefore, without postulating the bypassing of the arterio-venous anastomoses in the pulmonary vascularisation.

Although, so far as we know, no one has previously recorded fatty embolism after excision of the eye, it does not seem to be a rare occurrence. It is clear that routine histological examination would reveal no trace of the intruded fat. We can discover it only after investigation of the fixed and opened eye, preferably by the slit-lamp. Even then, the appearance of the milky bands might be overlooked (as certainly happened to us before we investigated the intra-vascular content) among the collapsed vessels.

We feel sure that systematic ophthalmoscopic investigation of injured patients, especially those with bone fractures (but possibly also without), will show this ophthalmoscopic picture to be frequent. It has escaped our attention as the retinal changes are transient, and do not as a rule leave any diminution of visual function behind.

\section{Summary}

Four cases are described in which enucleation or orbital exenteration was followed by fatty embolism of one or more branches of the central retinal artery. The embolism was more or less fluid, and consisted of a fine fatty emulsion which stained shining red with scarlet red. The fatty content of the central artery is assumed to be aspired from the orbital fat and emulsified by the blood. Fatty embolism of the central artery with white silvery retinal patches and superficial haemorrhages is relatively frequent in fractures of the long bones, and is probably the cause of Purtscher's traumatic retinal angiopathy. The proved fine emulsion of the fat in these four cases may explain the so far inexplicable passage of fat through the pulmonary capillaries.

\section{REFERENCES}

1. LeBer.-Die Krankheiten der Netzhaut. Graefe-Saemisch-Hess, Handbuch derGes. Augenheilkunde, Vol. VII, ii, p. 277.

2. Loewenstein.-Klin. Monatsbl.f. Augenheilk., Vol. XCVI, p. 62, 1936.

3. OPPOLZIR.-Arch.f. Klin. Chirurgie, Vol. CLXXIX, p. 176, 1934.

4. URBANEK. Arch.f. Ophthal. v. Graefe, Vol. CXXXI, p. 147, 1933.

We are indebted to Mr. Donald for the slit-lamp sketch, and Mr. Watt for photomicros. 